\title{
Modelling the Influence of Age Structure on the Forest Biomass Availability: A case study of Karbala forest, Western Mbadjini region of Comoros.
}

\author{
Onuorah Martins O. ${ }^{1}$, Azhar Mousssa ${ }^{2}$, Luyiga Suzan ${ }^{3}$ \\ ${ }^{1}$ Department Physical Sciences Kampala International University Uganda, P.O.BOX 20,000 Kampala \\ ${ }^{2,3}$ Department of Environmental and Biological Studies Kampala International University Uganda P.O.BOX 20,000 \\ Kampala
}

\begin{abstract}
In this work, a deterministic mathematical model for the Influence of human age structure on forest biomass availability, incorporating public enlightenment campaign parameter was developed and analyzed. The model consists of three autonomous differential equations for the forest biomass, Junior and Adult populations. The Zero, Junior and Adult free as well as the interior equilibrium states of the model were obtained and analyzed for stability. Numerical simulation of the various model parameters were obtained using mat lab software. The simulation gave the public enlightenment coverage level that would guarantee high forest biomass density and thus optimum yield.
\end{abstract}

Key words: Forest, biomass, Density, Stability, Equilibrium.

\section{Introduction}

Forest presents a myriad of resources, benefits and values to Human being. It plays a very important role to the survival of people that mostly surround it. Karbala forest in Western Mbadjini region of Comoros, provides people with their daily needs such as wood for fuel, construction, fences, charcoal and crafts; plant materials for medical/religious uses, fodder, thatching grass and food products such as fruits and honey. The forest provides also many indirect benefits: it improves environment around settlements, it provides people with safe and clean drinking water and it filters air as to provide clean and fresh air to the population.

Human agents of landscape transformation in the tropics affect forests differently as the forests decline in size; Thomas (2006). The Karbala forest resources are shrinking in a dizzying pace due to unchecked activities of the surrounding population. From 2000 to 2010, the rate of deforestation in Comoros reached $9.3 \%$ per year, which is one of the highest rates in the world. Between the years 1900 and 2005 Comoros has continually lost 7000ha (58.33\%) of its forest Purnomo et al. (2003). If there is no immediate intervention to mitigate these activities, deforestation can result in the extinction there by denying the communities of the intended benefits of this natural resources.

Forest Management is the way that forests and the trees within them are protected and used to provide forest products and other benefits Sourabh et al. (2014). Therefore Forest management is done to ensure sustainable yield thus conserving the forest. However, forest management has been unsuccessful from historic time up to nowadays in some countries in Africa Nasi et al. (2006). Forest management in Ghana has been abortive due to lack of considering community people in what could be done to save the forest such as forest plan or regulation Kufuor (2000). Population surrounding the forest is the most threat to the forest but they are also a solution to its 
survival in forest management. For a decade, forestry companies in Central Africa are increasingly engaged in a quest for more sustainable forest harvesting by developing integrated forest management plans. But this has resulted in little growth of the forest as the forest management plan did not take all stakeholders into consideration Nasi et al. (2003).

Globally, forest management attention seems now to have generally been shifted from management for a single objective to a sustainable ecosystem approach that tries to incorporate the principles of equity in resource utilization and participation for sustained production of multiple outputs into forest management by recognizing the hopes and aspirations of different stakeholders interested in the future of the natural forest resources Tracey et al. (1999).

Scholarly work on general forest management abound in the literature; for instance, Dhar and Singh (2004); noted that forest has to be managed by all stakeholders. He further noted that recognizing any kind of activity exerted by people surrounding the forest would ensure a good forest management that results in multiple effective outputs and sustainable yield. Budhi et al. (2004); annotated that forest management should be done with the participation of the people especially community population surrounding the forest.

Similarly, articles in mathematical modeling of forest resources also abound in the literature, for instance Shukla et al. (2011); proposed and analyzed a nonlinear mathematical model to study depletion of forest resources caused by population and population pressure augmented industrialized. Their model, showed that, as the density of population or population pressure increases, the cumulative density of forest resources decreases, and the resources may become extinct if the population pressure becomes too large. It is also noted that by controlling the population pressure, using some economic incentives, the density of forest resources can be maintained at an equilibrium level, which is population density dependent.

Agarwal and Pathak (2015); proposed a mathematical model for the conservation of forest biomass with wood based industries and synthetic industries. They suggested the promotion of synthetic industries over the wood based industries to save our forest environment. Dubai et al. (2009); modelled the depletion of forestry resource by wholly dependent industrialization in two adjoining habitat. Chaudhary (2013); modelled the depletion of forest resources by population and industrialization and their conservation by green belts plantation. Further, Lakshmikantham (2000); studied the conservation of forest biomass by using alternative resource.

The articles cited above did not considered the fact that sub-populations in a community have varying degree of impact on the forest resources by their activities. It is obvious that young populations have not the same amount of influence on the forest as mature population who directly affect the forest negatively or positively. This article is aimed at identifying the effects of the activities of different age-groups of the population on the forest. This will be done by extending existing models to include the Junior and Adult human sub-population and incorporating public enlightenment parameter to the forest biomass equation. 


\section{Materials and methods}

\subsection{Model formulation}

The forest biomass is assumed to grow logistically with carrying capacity $K$ and intrinsic growth rate $r$, such that the forest biomass is recruited by $r F\left(1-\frac{F}{K}\right)$, where $F$ is the cumulative density of the forest biomass at time $t$. The forest biomass resources have a natural depletion rate $\alpha$ and also is depleted by the activities of adult citizens of the surrounding community by a rate $\alpha_{1}$. A major parameter in the forest biomass is the public enlightenment coverage $\rho$. Educating the communities surrounding the forest on adverse effect of indiscriminate harvesting of the forest resources helps to keep the forest healthy.

The population of the communities surrounding the forest is divided into two. The junior members of population age $<15$ and adult populationage $\geq 15$. The junior population is recruited by birth rate $\beta$, members progress to adult population at the rate $\sigma$ and can exit out naturally before becoming adult at the rate $\delta$. The adult population obviously is generated by the junior sub-population at rate $\sigma$, and by immigration attracted by the forest resources and ends his/her journey by natural death at the rate $\delta$.

Putting the above into perspective we come up with the following three ordinary differential equations for Karbala forest resources management.

$$
\begin{aligned}
& \frac{d F(t)}{d t}=r F\left(1-\frac{F}{K}\right)-\alpha F-\rho \alpha_{1} F N_{A} \\
& \frac{d N_{J}(t)}{d t}=\Lambda-\sigma N_{J}-\delta N_{J} \\
& \frac{d N_{A}(t)}{d t}=\sigma N_{J}+\beta F N_{A}-\delta N_{A}
\end{aligned}
$$

Table 1. Parameters and their meaning

\begin{tabular}{ll}
\hline Variables/parameters & Meaning \\
\hline$F$ & Cumulative density of the forest resources. \\
$N_{J}$ & Cumulative density of junior population at time t. \\
$N_{A}$ & Cumulative density of adult population at time t. \\
$r$ & Intrinsic growth rate of the forest biomass. \\
$K$ & Carrying capacity of the forest. \\
$\rho$ & Public enlightenment coverage. \\
$\boldsymbol{C}$ & Natural depletion rate of the forest biomass resource \\
$\alpha_{1}$ & Forest depletion rate due to adult population.
\end{tabular}


$\sigma$

$\beta$

$\Lambda$

$\delta$
Progression rate from junior to adult population.

The growth rate of adult population due to forest resources.

Recruitment rate (crude rate) Birth.

Natural death rate (crude rate) of human.

$N=N_{J}+N_{A}$, such that

Lemma 1 The closed set $D=\left\{\left(F, N_{J}, N_{A}\right) \in R_{+}^{3}: F \leq K ; N_{J}+N_{A} \leq \frac{\Lambda}{\delta}\right\}$ is positively invariant with respect to the model equations (1) to (3).

\section{Proof}

From equation (1) we have;

$$
\frac{d F(t)}{d t} \leq r F\left(1-\frac{F}{K}\right)
$$

By adding equation (2) and (3) we have

$$
\frac{d N(t)}{d t} \leq \Lambda+\beta F N_{A}-\delta N
$$

It follows that $\frac{d F(t)}{d t}<0$ and $\frac{d N(t)}{d t}<0$ if $F(t)>K$ and $N(t)>\frac{\Lambda}{\delta}$, respectively. Thus a standard comparison theorem as in [17] can be used to show that $F(t) \leq F(0) e^{-(t)}+K\left(1-e^{-(t)}\right)$ and $N(t) \leq N(0) e^{-\delta(t)}+\frac{\Lambda}{\delta}\left(1-e^{-\delta(t)}\right)$. In $\quad$ particular, $\quad N(t) \leq K$ and $\quad N(t) \leq \frac{\Lambda}{\delta} \quad$ if $F(0) \leq K$ and $N(0) \leq \frac{\Lambda}{\delta}$ respectively. Thus $D$ is positively-invariant. Further, if $F(0)>K$, and $N(0)>\frac{\Lambda}{\delta}$, then either the solution enters $D$ in finite time or $F(t)$ approaches $K$, and $N_{R}(t)$ approaches $\frac{\Lambda}{\delta}$. Hence $D$ is attracting, that is all solutions in $R_{+}^{3}$ eventually enters $D$. Thus in $D$, the basic model equations (1) to (3) is well posed ecologically and mathematically according to Hetcote (2000). Hence it is sufficient to study the dynamics of the basic model equations (1) to (3)

\subsection{Equilibrium states of the model}

The model has four equilibrium; the trivial equilibrium $E_{0}(0,0,0), E_{1}\left(K\left(1-\frac{\alpha}{r}\right), 0,0\right)$ 
$E_{2}\left(K\left(1-\frac{\alpha}{r}\right), \frac{\Lambda}{\sigma+\delta}, 0\right)$, and $E_{3}^{*}\left(F^{*}, N_{J}^{*}, N_{A}^{*}\right)$

We obtain the arbitrary pointes of the interior equilibrium by setting the left hand side of (1) to (3) to zero and solve as follows;

$$
\begin{aligned}
& r F^{*}\left(1-\frac{F^{*}}{K}\right)-\alpha F^{*}-\rho \alpha_{1} F^{*} N_{A}^{*}=0 \\
& \Lambda-\sigma N_{J}^{*}-\delta N_{J}^{*}=0 \\
& \sigma N_{J}^{*}+\beta F^{*} N_{A}^{*}-\delta N_{A}^{*}=0
\end{aligned}
$$

Form (7),

$$
\begin{aligned}
& \Lambda-\sigma N_{J}^{*}-\delta N_{J}^{*}=0 \\
& N_{J}^{*}(\sigma-\delta)=\Lambda \\
& N_{J}^{*}=\frac{\Lambda}{(\sigma-\delta)}
\end{aligned}
$$

$$
N_{A}^{*}=\frac{\sigma N_{J}^{*}}{\left(\beta F^{*}-\delta\right)}
$$

Substituting (9) into (10) we have

$$
N_{A}^{*}=\frac{\sigma \Lambda}{\left(\delta-\beta F^{*}\right)(\sigma+\delta)}
$$

From (6),

$$
F^{*}=K\left(\frac{r-\alpha-\rho \alpha_{1} N_{A}^{*}}{r}\right) \text {. }
$$

Hence, $E_{3}^{*}\left(F^{*}, N_{J}^{*}, N_{A}^{*}\right)=\left(K\left(\frac{r-\alpha-\rho \alpha_{1} N_{A}^{*}}{r}\right), \frac{\sigma \Lambda}{\left(\delta-\beta F^{*}\right)(\sigma+\delta)}, \frac{\Lambda}{(\sigma-\delta)}\right)$

\subsection{Stability of equilibrium}

Theorem 1 the equilibrium states of the model is locally asymptotically stable provided that the eigen-values of the Jacobian (14) of the model equations are all negative

Proof.

By linearizing the model equations (1) to (3) as in Onuorah et al. (2016) we have the Jacobian. 
$J=\left[\begin{array}{ccc}r-\frac{r F^{*}}{K}-\alpha-\rho \alpha_{1} F^{*} N_{A}^{*} & 0 & \rho \alpha_{1} F^{*} \\ 0 & 0 & -(\sigma+\delta) \\ \beta N_{A}^{*} & \sigma & \left(\beta F^{*}-\delta\right)\end{array}\right]$

Evaluating (14) at $E_{3}^{*}$ we have the characteristic equation $\left|J_{E_{3}^{*}}-\lambda I_{3}\right|$ that is

$$
J=\left[\begin{array}{ccc}
r-\frac{r F^{*}}{K}-\alpha-\rho \alpha_{1} F^{*} N_{A}^{*}-\lambda & 0 & \rho \alpha_{1} F^{*} \\
0 & -\lambda & -(\sigma+\delta) \\
\beta N_{A}^{*} & \sigma & \left(\beta F^{*}-\delta\right)-\lambda
\end{array}\right]
$$

Let $k_{1}=r\left(1-\frac{F^{*}}{K}\right)-\alpha-\rho \alpha_{1} F^{*} N_{A}^{*}$

$$
k_{2}=\left(\beta F^{*}-\delta\right), \text { then }
$$

$$
\left|\begin{array}{ccc}
k_{1}-\lambda & 0 & \rho \alpha_{1} F^{*} \\
0 & -\lambda & -(\sigma+\delta) \\
\beta N_{A}^{*} & \sigma & k_{2}-\lambda
\end{array}\right|=0
$$

$\left(k_{1}-\lambda\right)\left|\begin{array}{cc}-\lambda & -(\sigma+\delta) \\ \sigma & k_{2}-\lambda\end{array}\right|+\rho \alpha_{1} F^{*} \beta N_{A}^{*}=0$

Simplifying we have

$$
\begin{aligned}
& \left(k_{1}-\lambda\right)\left[-\lambda\left(k_{2}-\lambda\right)+\sigma(\sigma+\delta)\right]+\lambda \rho \alpha_{1} F^{*} \beta N_{A}^{*}=0 \\
& \lambda^{3}+\lambda^{2}\left(k_{1}+k_{2}\right)+\left[k_{1} k_{2}+\rho \alpha_{1} F^{*} \beta N_{A}^{*}+\sigma(\sigma+\delta)\right] \lambda-k_{1}+\sigma(\sigma+\delta)=0
\end{aligned}
$$

If we let $a_{0}=1, a_{1}=k_{1}+k_{2}, a_{2}=k_{1} k_{2}+\rho \alpha_{1} F^{*} \beta N_{A}^{*}-\sigma(\sigma+\delta)$ and $a_{3}=\sigma(\sigma+\delta)$

Equation (18) becomes

$a_{0} \lambda^{3}+a_{1} \lambda^{2}+a_{2} \lambda+a_{3}$

Equation (19) gives a Routh array of

$$
\begin{array}{lll}
\lambda^{3} & a_{0} & a_{2} \\
\lambda^{2} & a_{1} & a_{3}
\end{array}
$$


$\lambda^{1} \frac{a_{1} a_{2}-a_{0} a_{3}}{a_{1}}$

$\lambda^{0} \quad a_{3}$

So the condition that all roots of (18) have a real part is that

$a_{1} a_{2}>a_{0} a_{3}$

The interior equilibrium of the model is locally asymptotically stable if and only if the inequality (20) is satisfied.

\section{Results}

\subsection{Numerical simulation}

The various parameters of the model defined in table 1 is simulated with the following values, Table 2. Parameters and their values

\begin{tabular}{lll}
\hline Parameter & Value & Reference \\
\hline$K==15$, & 40 & Estimated \\
$\alpha$ & 1 & Estimated \\
$\alpha_{1}$ & 15 & Estimated \\
$r$ & 10 & Estimated \\
$\rho$ & 0.1 & Estimated \\
$\sigma$ & 1 & Estimated \\
$\delta$ & 0.033 & CIA 2017 est. \\
$\Lambda$ & 0.00721 & CIA 2017est. \\
$\beta$ & 0.1 & Estimated \\
\hline
\end{tabular}

The following graphs were generated. 


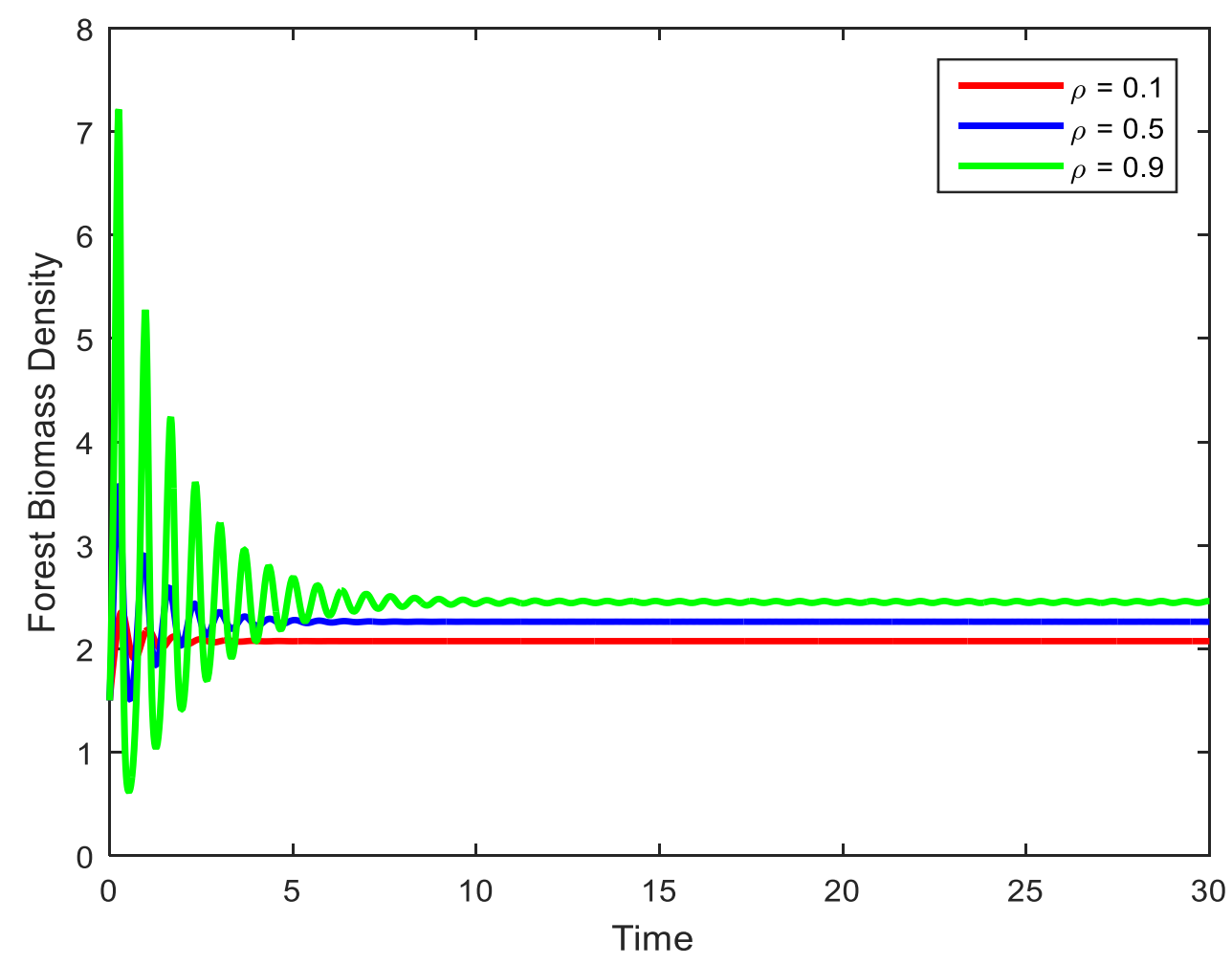

Figure 1. The forest biomass density $F$ is simulated with different values of public enlightenment coverage $(\rho)$ against time $(t)$. The simulation result shows a positive relationship between enlightenment coverage forest biomass. In other words, density of forest biomass increases with increase in enlightenment coverage. 


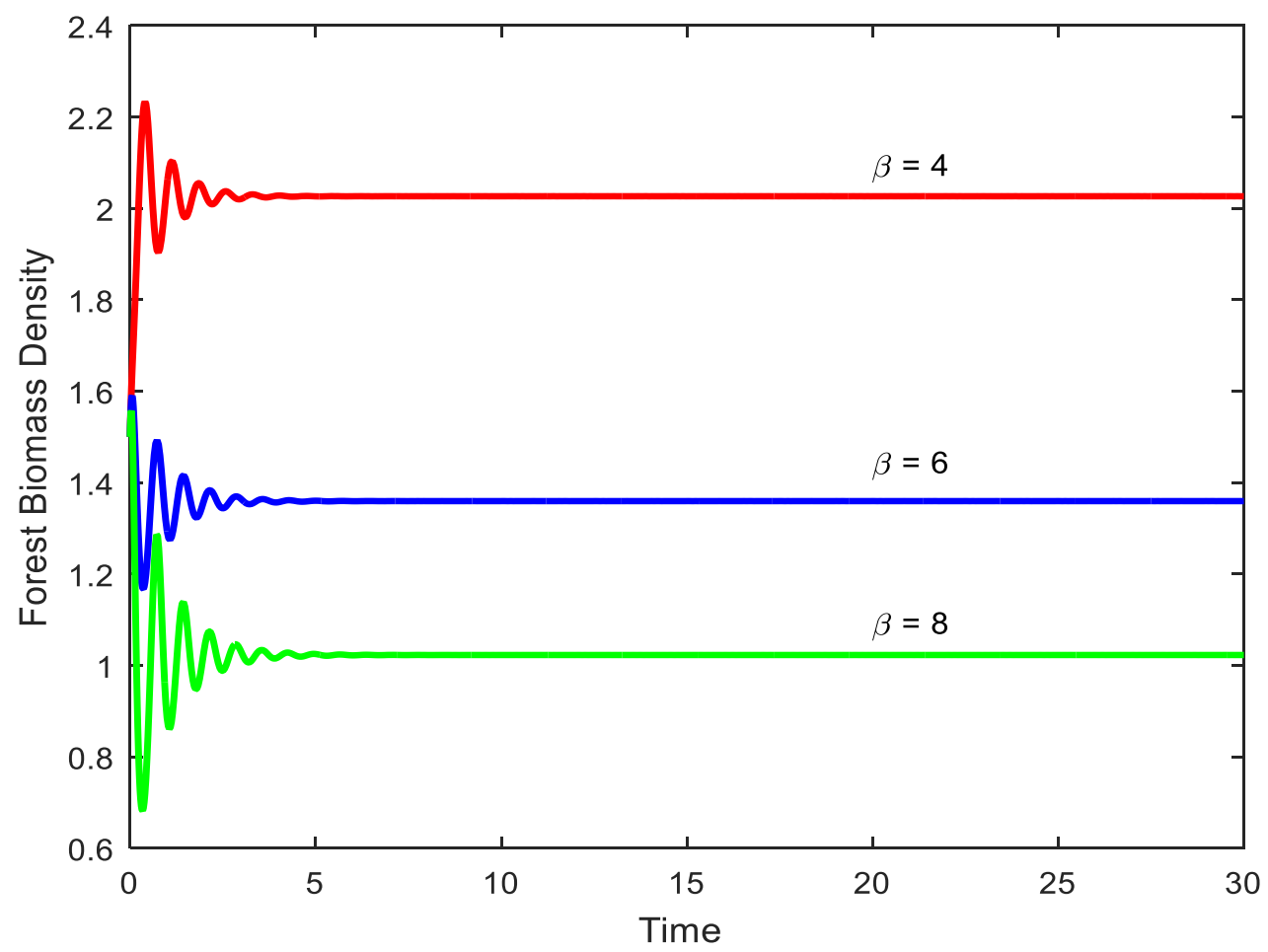

Figure 2. The simulation of forest biomass against time with different values of the growth rate of Adult sub-population due to forest resources $(\beta)$.

Adult sub-population is assumed to access the forest majorly therefore affect mainly the forest biomass. The simulation explains that increase in Adult sub-population growth rate leads to decrease in forest biomass. 


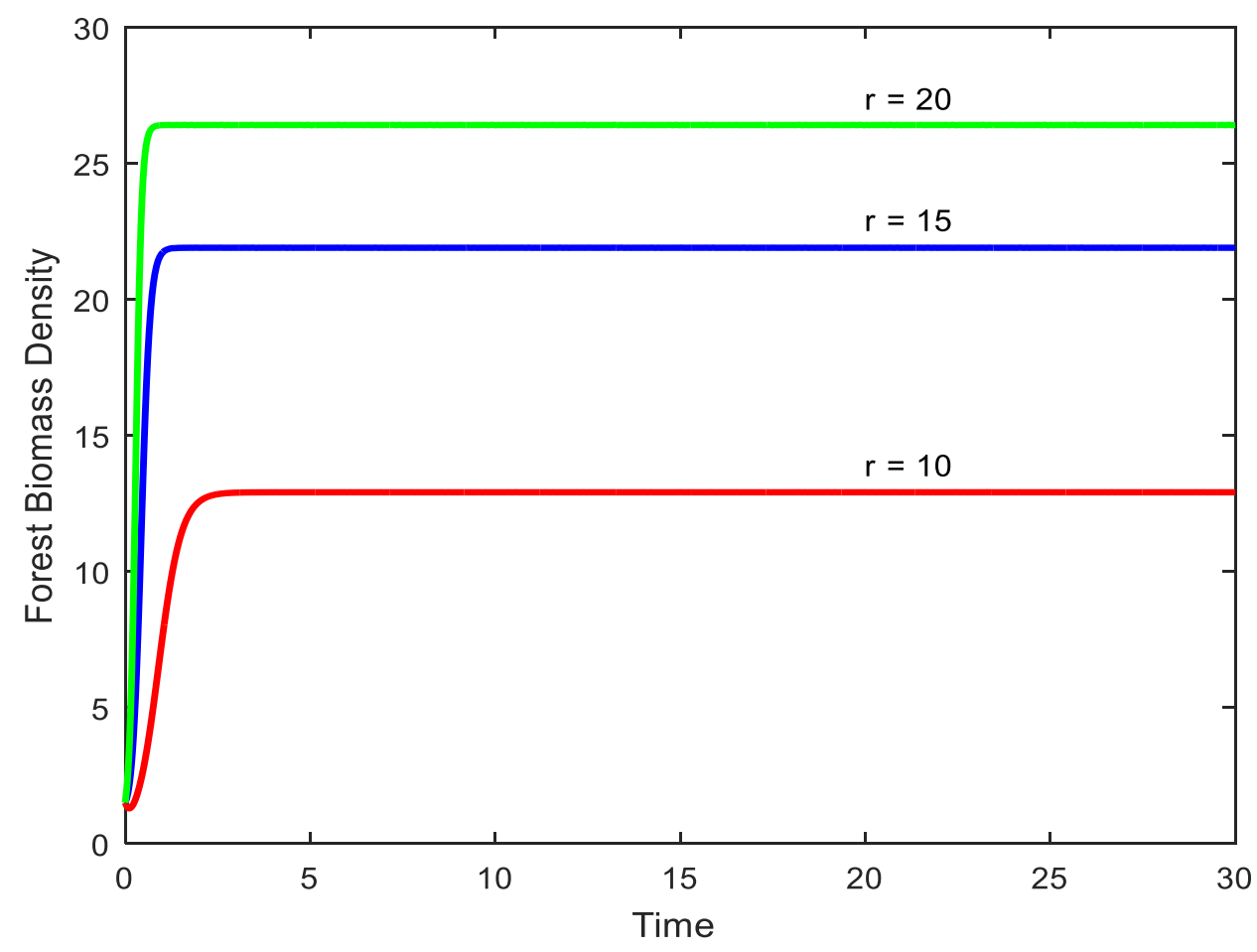

Figure 3.The simulation of forest biomass with different values of the intrinsic growth rate (r).

The simulation shows that increases in intrinsic growth rate (r) leads to increase of the forest biomass. It further implies that a rapid natural forest growth ensures an abundance of forest resources. 


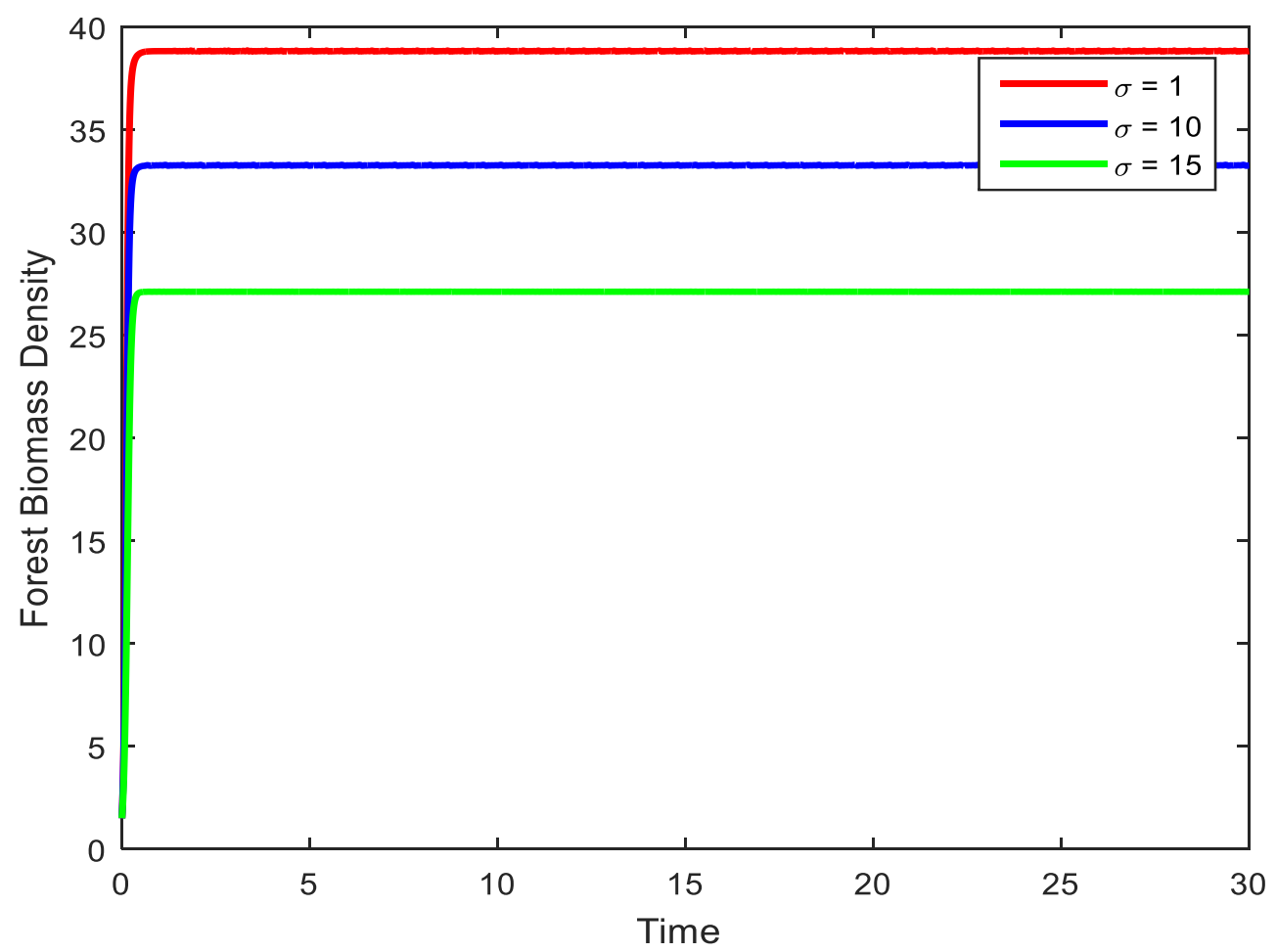

Figure 4. The simulation of forest biomass against time with different values of progression rate from Junior to Adult sub-population ( $\sigma)$.

The simulation shows a detriment of forest resources due to an increment of Adult subpopulation from Junior sub-population. 


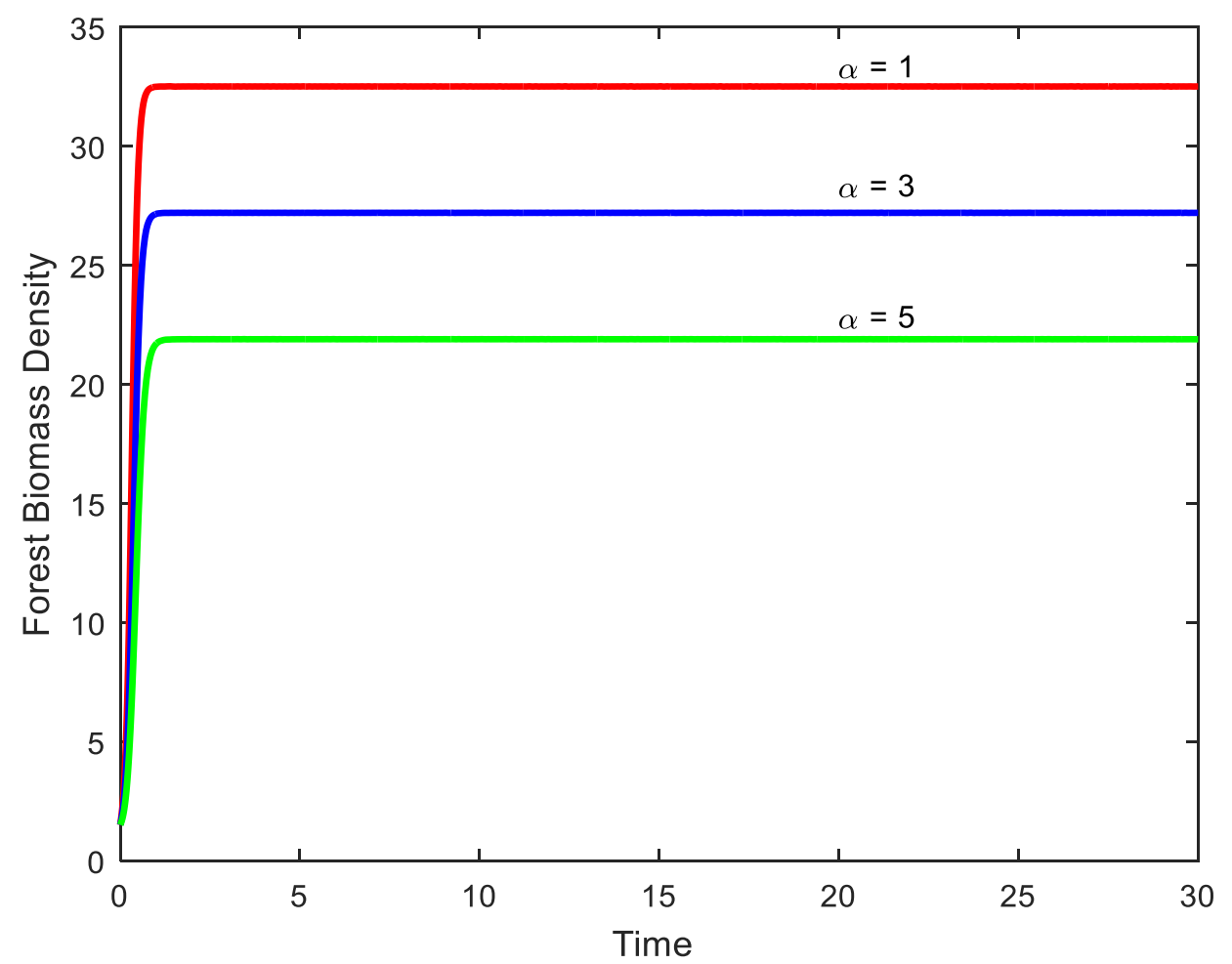

Figure 5. The simulation of forest biomass density against time with different values of natural depletion rate of the forest resources $\alpha$.

The simulation shows that the higher depletion rate leads to lower forest biomass density. 


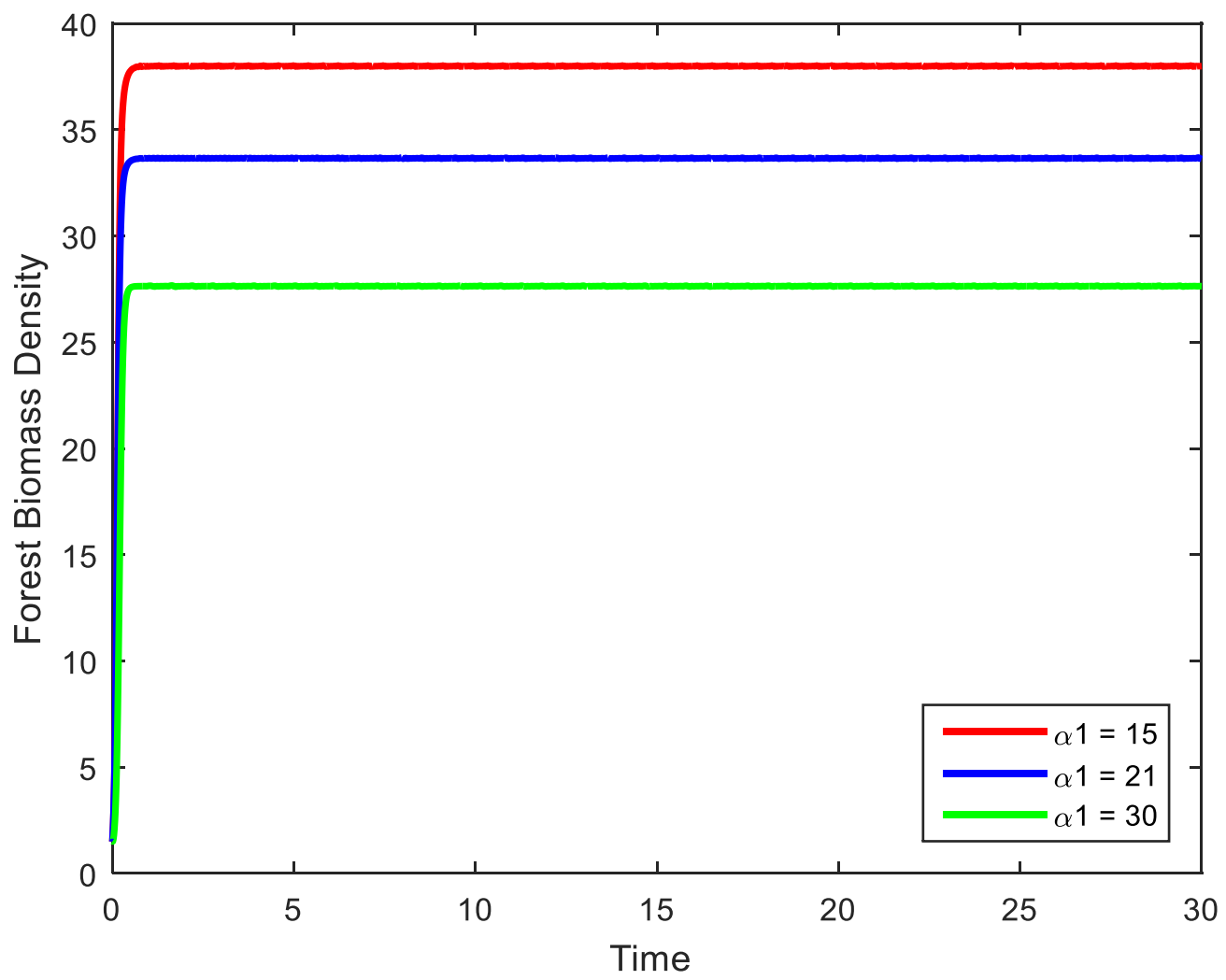

Figure 6. The simulation of forest biomass against time with different values of forest depletion rate due to Adult sub-population $\left(\alpha_{1}\right)$.

The simulation shows that higher forest depletion rate due Adult sub-population leads to decrease in forest biomass density. It further reveals that the activities of Adult sub-population diminish gradually the forest resources. 


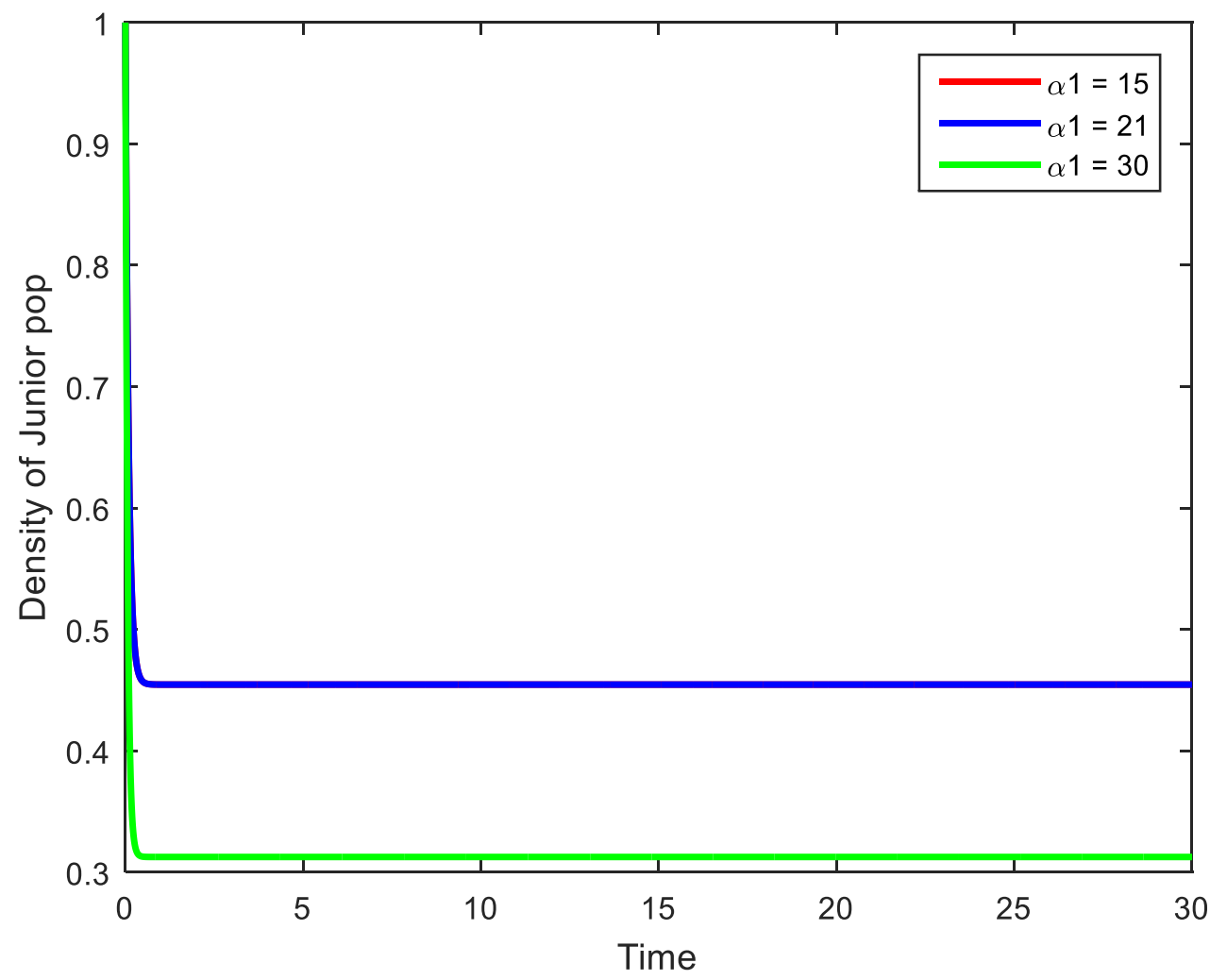

Figure 7. The Simulation of Junior population density against time with different values of forest depletion rate due to Adult population $\left(\alpha_{1}\right)$.

The simulation implies that Junior sub-population density decreases with increase in forest depleting rate due to Adult sub-population. 


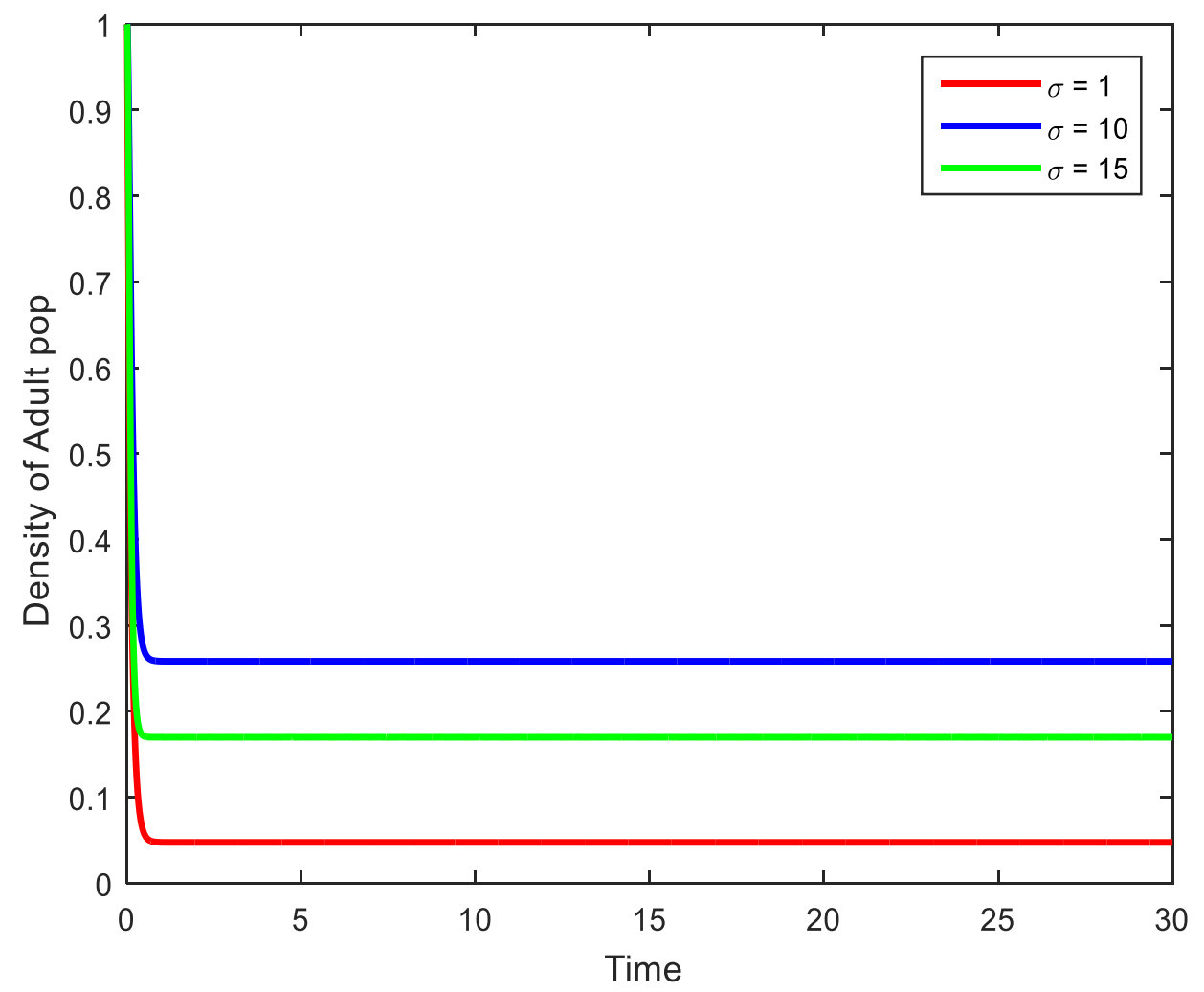

Figure 8. The simulation of Adult population density against time with different values of progression rate from Junior to Adult population $(\sigma)$.

The simulation implies that Adult population density increases with increase progression rate.

\section{Discussion}

Simulation of forest biomass density against time with different values of public enlightenment coverage $\rho$, figure 1 , shows that the density of the forest biomass increases with increase in enlightenment coverage. This means that to achieve high forest density, the entire forest community has to be educated on the dangers of indiscriminate cutting of the forest resources as well as the benefits of adhering to the forest regulation policy. This result is supported by Frederic (2004) who said that population growth and forest cover are unquestionably related; therefore human population has to be educated about the multiple values of the forest in order to save forest resources. This result was also supported by (PAI, 2014) reported that "educating people about the values and benefits of forests increases forest resources but also enhance millions of human lives. This is because, about 60 million people are wholly dependent on forests while more than 350 million people largely depend on forest areas for subsistence and income. This is to so that one of the incorporated parameters has been found to be necessary for forest biomass availability. The effect of intrinsic growth rate and most parameters are natural and are supported by most of the reviewed papers. 


\section{Conclusion}

The researchers developed a mathematical and ecological well posed model to study the effects of the activities of the surrounding communities on Karbala forest biomass. This was done by representing the interaction of the forest biomass, the Junior and Adult population using three non-linear ordinary differential equation. The model equilibrium states were obtained and analyzed for stability. Further, the various model parameters were simulated to identify key model parameters. The analysis of the model reveals that increase in public enlightenment coverage will result in increased forest biomass figure 1. The forest wellbeing and hence optimum yield can be achieved by the forest management if a wider and regular public enlightenment of the communities around the forest is maintained. It is worthy of mention that the introduction of the public enlightenment parameter could be responsible for the stability of the graph as they all become constant after a certain level of activity with time.

\section{References}

Agarwal, M., Pathak R. (2015) Conservation of Forestry Biomass with the Use of Alternative Resource. Open Journal of Ecology. Vol. 5, pp 87-109.

Amani J. U., Paxie W. C. Pierre A. A. and Lawrence M. (2018). Forest management and conservation before and after the introduction of village participatory land use plans in the Kilosa district REDD+ initiative, Tanzania. Journal of Sustainable Forestry, Volume 38, - Issue 2.

Budhi.G., Kazuhiko.T., Atsushi, T., and Oekan, S. A. (2004). Community Dependency on Forest Resources in West Java, Indonesia: The Need to Re-Involve Local People in Forest Management, Journal of Sustainable Forestry, Volume 18, - Issue 4.

CIA (2017) World fact book.

Dhar, J., Singh, H. (2004). Modelling the depletion of forestry resource by wholly dependent industrialization in two adjoining habitat. Kobe J Math 21(1) pp. 1-13.

Dubai. B., S. Sharma and P. Sinha J.B Shukla. (2009). Modeling the depletion of forestry resources by population and population pressure augmented industrialization. Applied mathematical modeling. vol. 33 pp 3002-3014.

Chaudhary, M., Dhar, J. (2013). Forestry biomass conservation with synthetic industry: a mathematical model. In: Engineering (NUICONE), 2013 Nirma University international conference on IEEE, pp 1-5

Fabusoro. E., Maruyama ,M., Shoyama K. and Braimoh, A. K. ((2014). Community Institutions, Sustainable Forest Management, and Forest Cover Change in Southern Japan, Journal of Sustainable Forestry, Volume 33. - Issue 1. Published Online: 17 May 2014.

Frederick A.B. (2004). Population growth and deforestation: A critical and complex relationship

Hethcote, H. W. (2000). The mathematics of infectious diseases, SIAM Review, vol. 42(4) pp. 599-653. 
Kufuor, K. O. (2000) Forest management in Ghana: towards a sustainable approach. Journal of African Law, 44(01) 52-64.

Lakshmikantham, V., Leela, S., and Martynyuk, A. A. (1999). Stability Analysis of Non-linear Systems, 164. New York and Basel: Marcel Dekker, Inc.

Nasi, R. and Forni, E. (2003). La gestion durable des forêts. Le Flamboyant 56, 39-40.

Nasi, R., Cassagne, B., and Billand, A. (2006) . Forest management in Central Africa 15 Forest management in Central Africa: where are we? International Forestry Review Vol.8(1).

Onuorah, M. O., Ademu, A., Obi, E. I., and Hasheem, M.A.(2016). Deterministic Mathematical Model of Zika Virus. Resarchjournali's Journal of Mathematics, Vo. 3(3).

PAI, Population Action International. (2014). why population matters to forests, wwww.populationaction.org

Purnomo, H., Yasmi, Y., Prahbu, R., Hakim, S., Jafar, A. and Suprihatin. (2003). Collaborative modelling to support forest management: Qualitative systems analysis at Lumut Mountain, Indonesia', Small-scale Forest. 2(2) 259-275.

Shukla J.B., k. Lata, and A. k. Misra,(2011). Modelling the depletion of a renew-able resource by population and industrialisation: Effect of technology on its conservation, Natural Resource modelling, Vol. 24.

Sourabh, D., Abhijit, S., Koushik, M. and Dipankar, D. (2014). Community Structure, Biodiversity Value and Management Practices of Traditional Agroforestry Systems in Tripura, North East India. J Biodivers Manage Forestry Vol: 3 Issue.

Thomas, K. R. (2006). Shrinking Tropical Forests, Human Agents of Change, and Conservation Policy. Conservation Biology 20(6), pp. 1604 - 9. DOI: 10.1111/j.15231739.2006.00532.x

Tracey .L. K., Adrian .C. N., John H. T. and Richard T. (1999). The Potential for CommunityBased Forest Management in Chiapas, Mexico: A Comparison of Two Case Studie. Journal of Sustainable Forestry, Volume 9, Issue 3-4. 